\title{
ANALYTICAL, ASYMPTOTIC AND INTEGRAL REPRESENTATIONS FOR A DOUBLE SUM
}

\author{
ChaO-Ping Chen And Richard B. PARis
}

Abstract. We give an analytical representation for the double sum

$$
\sum_{1 \leqslant i<j \leqslant n} \frac{1}{[(n+i)(n+j)]^{k}}
$$

in terms of the polygamma functions, where $k$ is any given positive integer. Based on this result, we present an asymptotic formula as $n \rightarrow \infty$ and an integral representation for this sum.

Mathematics subject classification (2010): Primary 41A60; Secondary 40A05.

Keywords and phrases: Psi function; Polygamma functions; Bernoulli numbers; Asymptotic formula.

\section{REFERENCES}

[1] M. Abramowitz and I. A. STegun (EdS), Handbook of Mathematical Functions with Formulas, Graphs, and Mathematical Tables, Tenth Printing, National Bureau of Standards, Applied Mathematics Series 55, National Bureau of Standards, Washington, D.C., 1972; Reprinted by Dover Publications, New York, 1965.

[2] H. M. SRivastava And J. Choi, Series associated with the zeta and related functions, Kluwer Academic Publishers, Dordrecht, Boston and London, 2001.

[3] H. M. SRivastava And J. Choi, Zeta and q-zeta functions and associated series and integrals, Elsevier Science Publishers, Amsterdam, London and New York, 2012. 